revista ANTHROPOLÓGICAS

Ano 23, 30(1): 38-68, 2019

\title{
Kretyen Sou Aparans: diferenciação e processos morais entre evangélicos no Haiti
}

Mézié Nadège

Quem é evangélico 'de verdade' e quem é só 'de aparência'? Neste texto, descrevo e analiso processos morais entre evangélicos de uma mesma igreja, numa comunidade rural do sudoeste do Haiti, onde a verdade da fé de cada um é colocada sob suspeita. Na malha de relações mediadas por uma missão norte-americana, o fogo-cruzado de acusações entre fiéis revela disputas por poder, competição por superioridade moral e uma maneira de exprimir as preocupações morais que não toma a forma da 'autorreflexividade' e da culpabilidade tão comum em contextos protestantes. $O$ pecado está nos outros, e acusá-los não deixa de ser uma ocasião para afirmar a sua própria virtude.

Moral, Evangélicos, Fofocas, Haiti, Missão.

Neste artigo não proponho uma leitura de como meus interlocutores, camponeses evangélicos do sudoeste do Haiti, tentam fazer o que eles consideram verdadeiro ou bom, mas sim de como eles avaliam e julgam o que consideram como comportamentos ruins ou falsos de outros, seus correligionários. Nas montanhas ${ }^{1}$ do departamento da Grand'Anse, nos atos de fala cotidianos (conversas, fofocas, brigas), protestantes ${ }^{2}$ criticam incessantemente os compor-

a Doutora em Antropologia (Universidade Paris Descartes). Bolsista 'Jovem Talento' (CAPES-Print/ PUCRS). Pesquisadora associada do Núcleo de Estudos da Religião (UFRGS) e do Centre d'Anthropologie Culturelle (Paris Descartes). Email: nadege.mezie@wanadoo.fr. 
tamentos, as crenças e as ações de outros protestantes, de sua própria igreja ou de outras. Ancoram suas apreciações em normas e regras oriundas de materiais escritos, como a Bíblia e livretos evangélicos, ou orais como sermões e falas mais informais de pastores, pregadores e professores da escola bíblica dominical, sem deixar de emprestar elementos de provérbios e da cultura camponesa haitiana de forma mais geral. Compõe, a partir desse universo discursivo compósito, uma moral evangélica local, ou o que poderíamos pensar, nos termos de Jarrett Zigon, como um "public discourse of morality", já que trata-se de "everyday articulated beliefs, opinions, and conceptions [of morality]" não diretamente dirigidas por uma instituição (Zigon 2009:259).

A minha análise aproxima-se daquela proposta por Paul Brodwin (1996) sobre os julgamentos morais a respeito de religião e de práticas de cura entre moradores de uma pequena cidade do sul do Haiti, num contexto de pluralismo religioso e terapêutico. Mas se eu me concentro no universo (de uma igreja) evangélica, Brodwin interessa-se pelas construções retóricas da diferença religiosa, considerando a competição pela superioridade moral e pela eficiência do poder de cura entre católicos, protestantes, servidores dos lwa (ou loa - espíritos do Vodu) e aqueles que combinam catolicismo e culto aos lwa.

Para entender as cenas acusatórias repetidas que presenciei, utilizo o conceito analítico de processo, não para remeter a uma judicialização dos conflitos, nem a uma midiatização ou publicização das acusações (como é o caso dos processos-affaires, estudados por Luc Boltanski³), mas para dar conta da extensão do fenômeno no tempo (não são acusações ou julgamentos pontuais), do seu caráter repetitivo e quase sempre recíproco e do seu poder de dinamização das relações sociais. Os processos podem ser apreendidos como sistemas de comunicação, que articulam diferentes atores, cada um perseguindo objetivos distintos. Para entendê-los melhor, é preciso considerar não somente os enunciados das acusações e contra-acusações, mas tam- 
bém seu contexto de enunciação e as posições sociais dos locutores, elementos que uma abordagem pragmática permite trazer à tona.

Uma utilização similar do termo é feita por Gérard Althabe (2003), ao tratar das relações entre vizinhos de um conjunto habitacional na periferia de Nantes. O autor mostra o trabalho constante de diferenciação dos vizinhos que cada família opera, através de um jogo retórico de acusações e defesas, que ele qualifica de processos. $\mathrm{O}$ cotidiano desse conjunto habitacional fica, assim, caracterizado pela divisão e os atos de fala de seus moradores pela omnipresença de processos recíprocos. As pessoas passam boa parte de seu tempo maldizendo as outras através de fofocas, tentando sujar sua reputação ("eles não cuidam dos filhos", "são uns assistidos", "ali ninguém trabalha", etc.) e, ao mesmo tempo, construindo para si, por oposição, uma boa reputação ("ao contrário deles..., minha casa é limpa", "meu marido tem emprego/sou trabalhador", "meus filhos estão longe da delinquência”, etc.). Esse termo me pareceu assim útil para considerar as dinâmicas de acusação e contra-acusação entre camponeses evangélicos haitianos, que põe em jogo e em disputa a qualidade da identidade de kretyen de cada um.

Kretyen, literalmente 'cristão', em crioulo haitiano pode significar um ser humano (fala-se então de kretyen vivan, sinônimo, neste caso, de nèg), ou, de forma mais restrita, um protestante (de qualquer corrente ou denominação). O termo não é, no entanto, utilizado para designar católicos (katolik), como é o caso da palavra 'cristão' em português. Por esta razão, conservo, ao longo do texto, o termo em crioulo kretyen. No mundo camponês protestante haitiano, a figura oposta, em termos morais, ao de kretyen é o de servidor dos lwa. O fato de servir os lwa e o Vodu funcionam, nos processos morais, como o polo negativo, repelente, do qual todos querem ser percebidos como o mais afastado possível e, perto do qual tentam situar inimigos ou adversários.

A condenação do Vodu, assim como a condenação de diferentes costumes populares (plasaj $j^{4}$, jogos de dinheiro, briga de galo, e tudo que se refere à banbòch - festa - como o consumo de álcool e tabaco), 
prolonga os discursos e práticas de autoridades coloniais e do período pós-independência. A Igreja Católica até o Concilio Vaticano II (1962-1965), e os diferentes governantes do país, até o reconhecimento do Vodu como religião pelo Estado haitiano em $2003^{5}$, tentaram eliminar, em particular através de campanhas antisuperstição, essas crenças e práticas que eram associadas às 'trevas', ao 'canibalismo' e à 'barbárie' e que atrapalhavam, segundo os governantes e o clero, o progresso e a modernização do país (Hurbon 1988; Ramsey 2011; Clorméus 2012). Se a partir dos anos 1970 a Igreja Católica tem sido mais conciliante com práticas oriundas de outras religiões, os sermões de pastores e missionários protestantes por todo o país são povoados de condenações inflamadas contra tudo que remete ao universo do Vodu. A própria insistência dessas falas evidencia o quanto a renúncia a essas práticas, consideradas como supersticiosas e do domínio do pecado, não é um fato consumado na vida cotidiana de muitos convertidos no Haiti e na diáspora haitiana (Richman 2008).

Porém, os processos que nos ocuparão aqui não opõem os cristãos e os servidores dos lwa, nem mesmo católicos e protestantes, mas sim os 'irmãos ${ }^{6}$ protestantes entre si, porque, como me disse um dos meus interlocutores: "Há diferentes tipos de kretyen". As acusações e contra-acusações podem visar um indivíduo ou um coletivo, elas acontecem com frequência entre membros de diferentes igrejas, correntes, movimentos ou denominações protestantes. Já os processos que descrevo aqui, são aqueles entre membros de uma mesma igreja. Neles, se discute e se discorda sobre quem é um "verdadeiro kretyen (vrè kretyen)", ou um kretyen só "de aparência (sou aparans)", "que só esquenta o banco da igreja”, etc. Esses processos podem ser lidos, de fato, como um trabalho de apreciação moral do mundo através de categorias que funcionam em par: verdadeiro/falso, aparência/interior, dentro/fora, ser sincero-conforme/enganar-mentir. $\mathrm{O}$ conjunto de processos que será descrito neste texto tem ainda uma outra particularidade: envolvem todos uma mulher, Madan Olsen, uma das figuras chave de sua igreja-missão, e se inserem num contexto de crise e de mudança, quan- 
do antigos líderes são destituídos e acirram-se disputas por posições de prestígio no seio da congregação.

Começo, assim, por apresentar o contexto no qual esses processos ocorrem. Descrevo o universo evangélico das montanhas do sudoeste do Haiti, com suas primeiras gerações de fiéis convertidos a partir dos anos 1940. Retrato a missão norte-americana que se instalou no vilarejo onde trabalho, Mòn Anvè, no início dos anos 1990 e as relações que se estabelecem entre missionários e locais. Trato, então, do gênero de comunicação privilegiada desses processos, as fofocas, e detalho o seu conteúdo, apresentando as categorias vernaculares utilizadas por meus interlocutores. A partir deste quadro geral, abordarei os processos intentados contra Madan Olsen ou por ela proferidos. Em conclusão, numa perspectiva comparativa, discuto algumas especificidades deste contexto evangélico camponês haitiano, onde a preocupação com o outro parece impor-se com mais força que aquela com seus próprios atos.

\section{'Velhas' famílias protestantes e recém-convertidos}

O protestantismo evangélico e pentecostal ganhou muitos fiéis nas três últimas décadas no Haiti (Mézié 2016). Igrejas adventistas do Sétimo Dia e grupos da Armée Céleste, também se multiplicaram (Corten 1998). Em diferentes localidades do país, o número de ounfò (templos vodu) diminuiu, muitas igrejas católicas se esvaziaram e as pessoas se dividem, integram diferentes elementos, ou circulam por essa pluralidade de oferta de serviços religiosos ${ }^{7}$. Mas antes desse momento mais recente de expansão intensa, igrejas protestantes já tinham feito sua aparição na paisagem religiosa haitiana.-

Nas montanhas do departamento da Grand'Anse, nos anos 1940, missionários estadunidenses e cubanos, auxiliados por haitianos que recém haviam voltado de plantações de açúcar em Cuba onde se tinham convertido ${ }^{8}$, trabalharam na implantação do protestantismo, principalmente de denominação batista. Igrejas foram construídas em 
diversos vilarejos nas montanhas e no litoral, a maioria afiliada à Missão Evangélica Batista do Sul de Haiti (MEBSH) que, hoje, possui e administra escolas, uma universidade, um hospital, clínicas e a Rádio Lumière, uma das principais rádios evangélicas do país. No vilarejo de Bernen, há 45 minutos de caminhada de Món Anvè, funciona desde 1964 uma igreja afiliada ao Corps $d u$ Christ (Corpo do Cristo), que se vinculou depois a outras missões. Muitos dos que se converteram nessa época viviam em vilarejos ou pequenas cidades (e não em terrenos dispersos pelas montanhas) e pertenciam a famílias camponesas com mais posses e, portanto, maior status social.

Quando novos missionários, principalmente norte-americanos, chegaram na região a partir dos anos 1980, em uma onda de evangelização que seguia um movimento protestante global (Corten e Marshall-Fratani 2001; Robbins 2004a), encontraram ali algumas 'velhas' famílias protestantes, ou seja, famílias em que a fé evangélica havia sido transmitida de geração em geração. Membros dessas famílias deram imediatamente seu apoio e desempenharam o papel de mediadores e facilitadores da implantação das missões. Sua identidade religiosa já consolidada facilitava a sua entrada rápida na missão e a conquista de cargos de liderança.

A tradição e continuidade da fé entre gerações eram, e ainda são, motivo de orgulho nessas famílias. Quem tem pais que já "tinham Jesus como salvador", anuncia com gosto ter "crescido numa família protestante (te fèt nan pwotestantism)", e se a conversão foi dos avós, com mais orgulho ainda se afirma ser "a terceira geração evangélica da família". Lembram sempre do ascendente que foi o pioneiro do que se tornaria uma linhagem de evangélicos, mais ainda se ele ou ela participaram da fundação de uma igreja ou missão. Christophe Pons, trabalhando com protestantes nas ilhas Faroé (entre a Escócia e a Islândia), observa que para fiéis de certas denominações, ter ascendentes protestantes também é uma fonte de prestígio social, enquanto em outras igrejas, calvinistas em particular, falar disso e mesmo ter esse sentimento de orgulho não seria bem visto, já que daria provas 
de pouca humildade (Pons 2011:8). Ali, e, sobretudo, nestas últimas igrejas, as heranças familiares são menos valorizadas que a "herança coletiva da congregação" (Pons 2011:8). A qualidade moral de uma pessoa está ligada ao seu engajamento pessoal com Deus e não ao vínculo com um ascendente ou ao pertencimento a uma determinada família.

De fato, a fé pensada como uma herança familiar não deixa de ser, em alguma medida, um paradoxo dentro do protestantismo evangélico, que se caracteriza pela conversão individual voluntária realizada na idade adulta - ponto destacado por diferentes correntes para se diferenciar do catolicismo. A conversão é considerada como uma 'ruptura' (Fath 2004) e as narrações mobilizam a retórica de uma descontinuidade radical entre um 'antes' e um 'depois' da conversão (Engelke 2004). Essa característica é perfeitamente operatória entre meus interlocutores, mas os membros das 'velhas' famílias se acomodam desse traço simplesmente localizando, nas narrativas, essa ruptura com o 'antes' gerações atrás, e não na sua própria vida. Uma vez a ruptura efetuada, bastou cada nova geração manter-se "no bom caminho (dwa chemen)" e não voltar às "velhas coisas (vye bagay)", em referência ao culto dos lwa. Pois efetivamente, o 'antes' da conversão, no caso de muitos camponeses haitianos, é um passado no Vodu. Os membros dessas velhas famílias protestantes podem então gabar-se de nunca ter "botado os pés num ounfō", de não saber nada "dessas coisas (bagay sa-yo)" que fazem parte de um mundo ao qual eles nunca teriam pertencido.

É como se as novas gerações das velhas famílias protestantes pudessem mostrar seu 'pedigree' evangélico que os teria protegido da contaminação 'supersticiosa'. As impurezas, reminiscências de um passado marcado por estas 'superstições' apagam-se pouco a pouco sob o efeito da sedimentação orquestrada pela transmissão intergeracional. Flavia Dalmaso, trabalhando em Jacmel (ao sul de Porto Príncipe, no litoral), relata uma postura similar de seus anfitriões batistas: eles se afirmam como 'verdadeiros cristãos' e buscam mostrar que há 
muitas décadas já não têm mais qualquer tipo de envolvimento com os lwa (Dalmaso 2018:110-111).

Já os novos convertidos têm que enfatizar a força e radicalidade desse momento de ruptura, que deve ser suficientemente intenso para sustentá-los no novo caminho. Para os membros das velhas famílias protestantes, os recém-convertidos são a prova do sucesso do trabalho de evangelização, do poder e da presença de Deus no lugar onde eles moram. Mas, ao mesmo tempo, suspeita-se que eles tenham aceito Jesus por interesse e estima-se que podem facilmente cair de novo na tentação ou voltar às "coisas diabólicas (bagay dyabolik)". Os recém-convertidos têm como dever reforçar a sua fé, mas também, diante das suspeitas contra eles, de provar a sua 'boa fé'. A relação entre velhas famílias e novos convertidos não deixa de lembrar aquela entre 'estabelecidos' e 'outsiders' de Winston Parva (Inglaterra), retratados magistralmente por Norbert Elias e John Scotson (1994).

\section{Uma concentração irradiante de riquezas e os missionários-patrões}

Em 1991 um casal de missionários, Pastè John e Madan John, estadunidenses afiliados a Evangelical Bible Mission (EBM), fundam um polo missionário em Mòn Anvè. A EBM, criada por uma família norte americana e ainda dirigida por membros da terceira geração dessa mesma família, é uma missão evangélica não denominacional, mas com afinidades importantes com a doutrina batista. Tem sua sede na Flórida e implantou-se, sobretudo, no Haiti e na Nova Guiné. Com a instalação da missão, Mòn Anvè se tornou, na percepção de seus moradores e daqueles das localidades vizinhas, uma 'zona protestante'. Já havia ali duas igrejas protestantes pentecostais que tornaram-se, então, satélites da missão. Os dois últimos ougan foram convertidos pelos missionários e a igreja católica acessível aos moradores (na divisa com o vilarejo vizinho), que já não era muito frequentada por moradores de Mòn Anvè, perdeu alguns de seus fiéis para a missão ${ }^{10}$. 
Naquele início dos anos 1990, havia em Mòn Anvè duas 'velhas famílias' de convertidos ao protestantismo, famílias que acabaram aliando-se por casamento. Membros dessas famílias deram um apoio fundamental para a instalação dos missionários. A vida da missão e suas próprias vidas ficaram, desde então, intimamente ligadas. Ao longo de quase três décadas, Pastè John, Madan John e esses primeiros fiéis construíram e melhoraram, aos poucos, o espaço missionário ${ }^{11}$. Em 2006, além da casa e quintal dos missionários e de um grande terreno adjacente $^{12}$, dentro do espaço cercado da missão havia: um templo, uma escola, um prédio com cantina, farmácia e quartos de hóspedes, a rádio local Laviktwa, dois reservatórios de água, um ateliê para diferentes trabalhos manuais ${ }^{13}$. A missão fornecia, em função do seu orçamento e das parcerias nos Estados-Unidos, uma série de serviços gratuitos aos moradores de Mòn Anvè e dos vilarejos vizinhos (independente da sua religião ou da frequência à missão): ajuda alimentar para as pessoas e famílias mais necessitadas, dom de roupas usadas, escolarização com refeição na cantina escolar para 100 crianças (uma grande parte deles apadrinhados por fiéis americanos), pagamento de custos de hospitalização na cidade de Okay ou de viagem para Estados-Unidos de pessoas com doenças graves, organização anual de uma medical week (vinda de médicos, dentistas e oftalmologistas dos Estados-Unidos durante uma semana). Evidentemente, o funcionamento de todos esses serviços exigia recursos humanos importantes. A missão contava com uma dezena de funcionários fixos, além daqueles que contratava pontualmente. A maior parte era recrutada entre os seus primeiros apoiadores.

Havia uma hierarquização entre os que trabalhavam ali. Quem assistia diretamente o trabalho dos missionários (o pastor, o assistente do missionário e a assistente da missionária, um administrador geral) ou trabalhava na casa deles (faxineira e babá) ganhava um salário fixo e tinha suas férias remuneradas. Estas posições conferiam prestígio aos seus detentores e espelhavam a posição de liderança que eles ocupavam na igreja. Os professores, o diretor e as cozinheiras da escola 
também recebiam um salário (do qual sempre reclamavam) e almoço de graça. Outros eram pagos em função da tarefa realizada e muitos, ainda, trabalhavam ali de graça, para 'reembolsar' uma hospitalização, agradecer os missionários por um favor recebido ou por vontade de ajudar. A missão era também uma distribuidora de posições de poder através das vagas de liderança nas diferentes atividades religiosas (cultos dominicais, orações de madrugada e de final de tarde quotidianas, diferentes corais, reuniões dos jovens e das mulheres, escola bíblica dominical...). Concentrava, assim, riquezas tanto espirituais quanto materiais, num "encaixe de profano e sagrado" (Mbembe 1993:183) comum à atividade missionária mundo afora ${ }^{14}$. Em Mòn Anvè como alhures, no espaço missionário, as riquezas materiais e espirituais se articulam, se sobrepõem e se consolidam reciprocamente.

Em Mòn Anvè, esses dois tipos de bens eram as duas faces de uma mesma moeda para muitos dos membros, que justificam seu lugar privilegiado dizendo que "toda essa benção, é Deus que a deságua, como uma chuva sobre nós". Até os anos 2000, os novos convertidos à igreja da missão pertenciam, sobretudo, a redes de parentesco dessas velhas famílias protestantes: eram sobrinhos, uma tia, um cunhado, o que reforçava o lugar de poder simbólico desse grupo que participou da fundação da missão. Essa concentração de bens e de posições de poder e sua circulação, que se fazia sob a supervisão clientelista do casal de missionários-patrões, provocava rivalidades, hostilidades e competições, que variavam de intensidade e de configuração com o tempo. No início do novo milênio a missão conseguiu expandir seu círculo de fiéis de maneira mais significativa e pessoas sem nenhum tipo de vínculo de parentesco com os primeiros fiéis começaram a frequentar a missão. Essa ampliação foi ao mesmo tempo motivo de orgulho para todos e fonte de novos conflitos. Em 2005 e 2006, uma crise até então latente eclodiu com a chegada de um novo pastor. Funcionários da missão foram demitidos, parte destes funcionários-fiéis foram também afastados de cargos de liderança na igreja e houve uma reestruturação do 'comitê da missão"15. 


\section{Fofocas, moral e rivalidades}

No contexto dessa crise, mas também em outras circunstâncias, as acusações feitas no âmbito dos processos morais que nos ocupam aqui são raramente feitas em público e ainda menos na presença do acusado. Elas tomam mais comumente a forma de discreet indiscretion para retomar o título do livro de Jörg Bergmann (1993) dedicado à organização social da fofoca.

No Haiti, para falar de fofocas as pessoas recorrem a uma antiga palavra francesa, tripotage, que foi se transformando, no crioulo, em tripotay, e sua abreviação, tripòt. Quando conversamos sobre o que eles entendem por tripotay, meus interlocutores costumavam começar por compará-la à oratória de um gran palè (grande falador), para depois diferenciá-la. Um 'grande falador' é alguém que fala muito e que gosta de falar muito. Pode ser alguém também considerado como versado na arte de falar bem, o que é extremamente valorizado, mas não necessariamente. $\mathrm{O}$ que o caracteriza em primeira instância é o seu fluxo de fala abundante, excessivo, ininterrupto. Em comum com o gran palè, aqueles que 'fofocam muito (tripòt anpil)' têm o que pode ser percebido como uma incontinência da fala. Singularizam-se, no entanto, já que fazer tripòt, dizem meus interlocutores, é falar mal de alguém na sua ausência, espalhar uma informação que deveria ser um segredo, produzir relatos mentirosos.

As fofocas são malvistas por todos, e os protestantes a condenam por ser o lugar da produção de mentiras, veículo de divisões e disparador de escândalos. No entanto, meus interlocutores não escondem o prazer que se pode sentir em falar mal de pessoas ausentes ${ }^{16}$. E todos confessam que o tripotay é uma prática omnipresente, que é uma 'coisa de haitianos ${ }^{117}$. Prova da banalidade dos tripotay, é a existência de inúmeros provérbios com a palavra e o fato de que ela pode, em certas ocasiões, ser usada como sinônimo de conversa, perdendo assim sua conotação pejorativa.

A relação das fofocas com a moral foi sublinhada em trabalhos clássicos da Antropologia (e também fora da disciplina ${ }^{18}$ ): seja na pers- 
pectiva de Max Gluckman em Gossip and Scandal (1963), para quem as fofocas reafirmariam normas morais, promovendo a coesão do grupo, seja na visão antagonista de Robert Paine (1967), segundo a qual as fofocas informam sim sobre a 'ordem moral' de um determinado grupo, mas servem essencialmente a interesses individuais e tendem a produzir mais fragmentação que unidade. Deixando em grande medida de lado essa preocupação com a função da fofoca, diversos antropólogos têm, atualmente, insistido sobre a importância de considerar, no estudo dos atos de fala, as posições sociais dos locutores (hierarquias, status) e o contexto de enunciação das falas (relações nas quais se inserem, disputas por poder, conflitos precedentes). Nas palavras de Alban Bensa, considerar "os discursos que se interpelam e se respondem no interior de um campo de interlocução bem definido no tempo e no espaço" (Bensa 2006:83).

Não se trata de dizer que tudo que está em jogo nos julgamentos morais (e mais ainda em julgamentos morais envolvendo religião) são disputas por poder, como se toda preocupação moral fosse, in fine, um pretexto para exprimir conflitos de outra ordem ${ }^{19}$. O que busco é explicitar as diferentes camadas de ação e de sentido que estão implicadas em tais julgamentos morais, pensando imbricações, ecos e superposições. Numa perspectiva similar a que adoto aqui, três trabalhos recentes (Brison 1992; Pietila 2007; Besnier 2009) articulam fofocas e moralidade, considerando, por um lado, as falas dentro de uma dinâmica discursiva ampla - o que poderia ser considerado uma 'economia da fala' própria a uma determinada sociedade - e, por outro, a influência que esses discursos sofrem e exercem sobre as relações de poder (político e econômico) nas quais eles se inserem. Interessam-se pelas inter-relações entre discursos públicos e privados (Brison 1992; Besnier 2009), pelo uso das fofocas por pessoas de poder (Brison 1992) ou, ao contrário, pelo emprego delas contra figuras de poder econômico e político (Pietila 2007). Pensam, como eu, a moral na sua construção cotidiana, através das falas. 
Mas os processos morais entre evangélicos haitianos que estudei não são unicamente veiculados através de fofocas. Esse é o gênero de comunicação mais frequentemente usado para acusar e para se defender, mas como veremos mais adiante, as acusações e contra-acusações podem também tomar outras formas.

\section{O objeto dos processos: o falso e o verdadeiro, o dentro e o fora}

No estudo de Brodwin (1996), praticantes de diferentes religiões opõem suas interpretações sobre as causas de uma doença e as possibilidades de sua cura. Ali, as disputas giram em torno do par inocente (polo positivo) /culpado (polo negativo). Tanto curadores quanto doentes podem ser suspeitos ou acusados de terem tido más intenções em direção de alguém (quis "destruir sua casa, sua família”, "o matar", muitas vezes recorrendo a feitiços), o que os tornaria culpados. O status moral de uma pessoa é balizado pela proximidade ou distância desses polos. E para os protestantes, ainda minoritários na zona na época da pesquisa de Brodwin (final dos anos 1980), o fato de recorrer à feitiçaria - e a um ougan - era suficiente para tornar alguém culpado.

Nos processos morais entre fiéis da EBM, o que está em disputa é o estatuto de verdade da identidade evangélica de cada um, e o par de opostos operatório é verdadeiro vs. falso. As condutas individuais são confrontadas a um modelo ideal de kretyen, caracterizado pela coincidência entre o 'fora' e o 'dentro'. Para ser um autêntico kretyen (kretyen otantik) é preciso sê-lo tanto nas suas ações quanto no seu foro interior. É preciso que haja sinceridade na sua obediência às ordens e normas decretadas pela Bíblia e proferidas nos sermões e falas dos pastores. Nas suas pregações, o missionário e o pastor insistem sobre a importância de "Viver a vida de Cristo", de não apenas frequentar a igreja, mas agir de acordo com a doutrina. Um dos textos mais discutidos, tanto nos sermões quanto na escola dominical, era a epístola de Tiago, que ressalta a importância das 'obras' como prova de fé, e, com sua força de exortação moral (Bernheim 2001), convida cada um a 
"guardar-se da corrupção do mundo" (Tiago 1:27)20. Nos discursos do missionário, essa 'corrupção' equivalia, sobretudo, a tudo que remete ao universo do $\mathrm{Vodu}^{21}$. O processo moral consiste então, tendo este modelo normativo como medida, no questionamento, contestação ou rejeição da qualificação de 'verdadeiro kretyen' de certas pessoas que dizem, no entanto, ter Jesus como seu salvador, que vão à igreja, que se converteram, ou que foram batizadas.

Os camponeses da região, qualquer que seja sua religião, compartilham a ideia de que há grandes chances da dimensão aparente da vida de uma pessoa (suas ações, sua imagem) não coincidirem com o seu interior. Assim, ir ao culto dominical, se apresentar publicamente como kretyen, é absolutamente insuficiente para ser reconhecido como 'vrè kretyen (verdadeiro kretyen)'. Há diversas expressões idiomáticas, e algumas improvisadas, para referir-se à falsidade ou ao a caráter pouco conforme da fé de cada um. Elas são em geral irônicas e metafóricas. São usadas no âmbito dos processos, com a intenção séria de difamar ou acusar alguém, mas também fora deles, para brincar, fazer piadas, falar da religião de maneira geral, tirar sarro, se mostrar provocativo... Fala-se de:

- konversyon sou $p^{22}$ : uma conversão superficial, que teria ficado 'só na pele';

- pwotestan du dimanch: um protestante que viria apenas ao culto de domingo;

- kretyen tanbou: um kretyen tambor, em referência ao caráter oco deste instrumento, vazio por dentro;

- kretyen sou aparans: kretyen de aparência;

- kretyen de chan: um kretyen de canto, ou seja que viria a igreja unicamente interessado pela musica e pela paquera;

- moun kap chofe ban: pessoa que só 'esquenta o banco da igreja' e não se sacrifica por Jesus na sua vida cotidiana;

- kretyen de John: um kretyen que só teria se convertido por interesse em frequentar a próspera missão do pastor John;

- kretyen tafia ou kretyen kleren: um kretyen-pinga, que não teria abandonado de fato o condenado costume de beber;

- kretyen tabak, que não deixou de fumar ou de cheirar rapé. 
Dos fiéis que continuam, ou são suspeitos de continuar, a servir os lwa se diz que eles têm "um pé dentro, um pé fora (yon pye andedan, yon pye andeyò)", que eles "banham-se em todos os molhos (benyen nan tout sòs) 23 ". Do lado oposto, se encontra o "verdadeiro kretyen" (vrè kretyen)", o "kretyen autêntico (kretyen otantik ) 24" aquele que diz "eu sou kretyen e nada mais do que isso (mwen se kretyen, m'pa anyen lòt)", "eu faço negócios somente com Deus, eu não vou do lado de lá, louvo a Deus com minhas duas mãos (mwen selman an afè avek bondye, m'pa konn ale lòt kote. Mwen rele'l avek dè men mwen)".

Há que se notar que essa preocupação com as falsas aparências não é nova. Ela remete a uma longa tradição moralista cristã, influenciada pelo estoicismo, que vai marcar de maneira particular o protestantismo puritano. Na Bíblia, a questão da falsidade (falso testemunha, falso caminho) não está ausente do Velho Testamento (11 ocorrências), mas é sobretudo no Novo Testamento (20 ocorrências) que o falso aparece, através do falso profeta ou apóstolo (por exemplo: Mateus 24:11; 24:24; 2 Coríntios 11:13; Mateus 7:15) e de uma forma corrompida de fé que deve ser combatida. $\mathrm{O}$ episódio mais marcante nesse sentido é, evidentemente, o das denúncias feitas por Jesus contra os fariseus e os doutores da lei (Mateus 23:13-15 e 23-28; Lucas 11:37-54) - o que faz do termo fariseu, ainda hoje, sinônimo metafórico de hipócrita. $\mathrm{O}$ protestantismo evangélico contemporâneo continua o combate contra a figura atualizada do fariseu, o 'modern-day pharisee ${ }^{25}$.

No final do Renascimento, com a multiplicação das edições e traduções de Sêneca, o estoicismo encontra novos admiradores e é de novo debatido (Lagrée 2010), em primeiro lugar por Calvino ${ }^{26}$ (Graves 2006; Lestringant 2006). Num contexto de emancipação e de luta com a Igreja Romana, os fundadores do protestantismo encontraram nessa corrente de pensamento da Grécia antiga regras de conduta úteis para alimentar a doutrina teológica em elaboração, como a da afirmação da alma como fortaleza interior inatacável (Todd 1983). O estoicismo terá, assim, uma influência significativa sobre a ética puritana (Todd 1983; Aggeler 1990). 
Para Webb Keane (1997 e 2002), o "ideal normativo de sinceridade" (2002:65) se tornou central no discurso de evangelização e na construção da pessoa protestante. Keane mostra como na ilha de Sumba (Leste da Indonésia), no início do século XX, os missionários calvinistas neerlandeses exortavam as pessoas a falarem com sinceridade, seguindo uma certa 'ideologia da língua' que postula, ao mesmo tempo, uma distinção clara entre 'exterior' e 'interior' e uma necessidade de tornar a primeira um espelho da segunda. Keane lembra as implicações 'ontológicas' e 'morais' desse tipo de ideologia: a sinceridade remete, de fato, ao que vem de "individual and internal sources" (Keane 1997:682), ao "from within" ou "from the heart" (Keane 1997:683).

Há, portanto, uma profundidade histórica importante desse debate. O que não impede que tenham havido evoluções e transformações diversas nessa relação entre o parecer e o ser, evoluções que diferem segundo as denominações e correntes e os seus locais de implantação. Basta pensar no aparecimento de uma moda pentecostal, que busca tornar visível a sua fé (Neal 2016) e afirmar um "tipo de comportamento coletivo exemplar, destinado a obter o reconhecimento do povo pentecostal como um povo santo" (Mafra 2014:180)27, ou na ostentação de bens materiais vista como afirmação da benção de Deus nas igrejas ligadas à 'teologia da prosperidade' (Oro et al. 2003). Esses fenômenos podem, por sua vez, engendrar críticas e acusações de falsidade, como mostra Jesse Shipley (2009) que observa pastores das igrejas carismáticas com 'doutrinas da prosperidade' em Accra (Gana) serem acusados de ser fake pastors.

O protestantismo sempre foi marcado por controvérsias numerosas e por fragmentações internas sucessivas. Essas divergências, não raro, se desdobram em processos morais visando os seus adversários. Determinar quem tem só uma 'falsa aparência', ou, ao contrário, quem segue 'verdadeiramente' a Bíblia, tem a 'verdadeira' doutrina cristã, envolve questões de poder e pode refletir posicionamentos de adesão ou resistência a mudanças. Assim, entre os Karavaran (Mela- 
nésia), são os novos convertidos, a maior parte jovens, afiliados a uma igreja evangélica conservadora, que acusam os membros de igrejas instaladas há mais tempo de serem excessivamente tolerantes com os 'costumes' (Errington \& Gewertz 1995). Já na Catalunha, os 'velhos protestantes' se recusam a integrar em sua associação, que reúne todas as igrejas de protestantismo histórico da região, os 'novos protestantes', ou seja, membros de igrejas pentecostais ou neopentecostais compostas e lideradas sobretudo por imigrantes, já que estes não seriam 'verdadeiros cristãos' (Griera 2008). Essas situações, assim como as que descrevo aqui, inscrevem-se, portanto, na ampla problemática do fake e da autenticidade na religião (Alberts 2008; Irons 2001; Copeman 2012), ou seja, de como analisar as imputações e práticas de imitação, enganação, trapaça, impostura ou falso engajamento (e o medo em relação a eles), tanto de fiéis quanto de líderes religiosos.

\section{Os processos de Madan Olsen}

Madan Olsen pertence a uma das velhas famílias de protestantes da região, também donos de terras e comerciantes. Sua avó se converteu nos anos 1950, graças a presença de uma igreja batista na cidadezinha cafeeira de Beaumont. Sua mãe, suas tias e tios foram "criados no protestantismo”, assim como ela e seus irmãos e irmãs. Quando a missão EBM chegou em Mòn Anvè, Madan Olsen (na época Selban, seu nome de solteira) tinha 17 anos. Com sua mãe, conhecida como Matante, e seus irmãos, foram seus principais apoiadores e primeiros funcionários. Aos 19 anos ela se casa com Olsen, que se torna, junto com dois de seus cunhados (casados com irmãs de Madan Olsen), verdadeiros pilares da missão em Mòn Anvè. Esses três casais ocuparam os principais papéis de liderança na igreja, todos os cargos do comitê e diversas funções remuneradas na missão.

Ao mesmo tempo em que trabalhavam na missão, Olsen e Madan Olsen continuavam a cultivar suas terras. Com ajuda de parentes da diáspora Olsen conseguiu comprar um caminhão e fazia fretes, levan- 
do produtos agrícolas da zona até Okay. Madan Olsen mantinha um comércio de fim de semana em casa e trabalhava como cozinheira e babá na missão (os missionários chegaram com um filho recém-nascido e tiveram outros quatro em Mòn Anvè). Seus próprios filhos, três, ela confiou a sua irmã, em Okay. Madan Olsen permaneceu no trabalho doméstico com os missionários até 2005, quando, durante minha estadia no vilarejo, precisou ser hospitalizada de urgência (para tratar de uma febre tifóide, seguida de malária). Ausentou-se então, com seu marido, por duas semanas do trabalho e disse ter pedido a Nelson (seu cunhado) que avisasse o casal de missionários da razão dessa ausência. Na sua volta, estes a demitiram alegando não ter recebido nenhum recado.

Após a demissão, Madan Olsen continuou, a custo de grandes esforços, frequentando o culto de domingo na missão, o que ela considerava seu "dever de kretyen". Passou ao mesmo tempo a dedicar-se em tempo integral ao comércio que mantinha em sua casa, que se tornou então o maior da localidade. Algumas semanas mais tarde, a mãe de Madan Olsen, Matante, foi afastada da liderança do coral de mulheres pelos missionários e uma de suas irmãs foi demitida da função de faxineira. Madan Olsen parou então de frequentar qualquer atividade na missão e nunca mais pôs os pés ali. Matante também ia cada vez menos na missão, até, não sem viver isso como um dilema, deixar de vez de comparecer ao culto dominical. Para Madan Olsen e Matante, os missionários teriam agido assim por dar demais ouvidos à fofocas e comentários pejorativos que certos fiéis faziam sobre elas e sobre pessoas de sua família. Em razão dessas fofocas, aliás, Olsen quase já não frequentava a missão, antes mesmo da demissão de sua esposa.

Pastor Alekson, era um dos que afirmava claramente (mas jamais na presença de Madan Olsen ou de alguém próximo a ela) que, na sua opinião, a família tinha "poder demais" e que era preciso "quebrar seu monopólio". Alekson era um jovem de Mòn Anvè, fiel da igreja da missão, que havia sido escolhido pelos missionários para ir a Porto Príncipe receber uma formação teológica de quatro anos para se tornar pastor na missão. Em julho de 2005 ele voltou desse período 
de estudos, casado com uma jovem evangélica de Porto Príncipe, e assumiu a função de pastor. Alekson não fazia parte das relações de parentesco dos Olsen e, ele me disse em uma conversa alguns dias após sua chegada, se sentia praticamente "em campo inimigo (terrain ennemi)" na igreja onde era pastor. Seu desejo era de "mudar muita coisa" no funcionamento da missão e ele buscava se aproximar e fazer alianças entre os fiéis recém convertidos.

Na Flórida, o reconhecimento do 'bom' trabalho missionário, que se traduzia em apoio financeiro à missão, dependia da sua capacidade de conquistar novos convertidos. Estes eram, assim, uma peça-chave da engrenagem missionária. Esses novos convertidos eram ainda mais valorizados caso sua história oferecesse um belo e dramático testemunho do "poder de salvação da fé" (que poderíamos pensar como um bom "apelo de marketing"). Sorel e Yonyon, dois antigos ougan convertidos pelo casal missionário, eram protagonistas de uma dessas histórias 'fortes'. Quando os dois eram ainda sacerdotes do Vodu, brigaram violentamente na noite de natal de 2002. Sorel deixou Yonyon agonizando na beira da estrada, depois de ter ateado fogo em parte do seu corpo. Madan John, que caminhava pelas casas nessa noite, encontrou-o e levou-o ao hospital. Sorel foi condenado pelo ataque e ficou preso por oito meses, o que praticamente correspondeu ao tempo que Yonyon passou no hospital. De volta à Mòn Anvè, ambos se converteram ao protestantismo, se perdoaram e uma narrativa evangélica do episódio foi construída: os dois se tornaram protagonistas ideais para reafirmar tanto o pertencimento do Vodu ao reino do Diabo, quanto o poder e a indulgência de Deus e de Jesus Cristo. Pastor John havia feito uma turnê com eles por diferentes igrejas no Haiti para testemunhar da "majestade do nosso Senhor". Pastor Alekson tinha se aproximado de Sorel, com quem Madan Olsen, como veremos, tinha tido quiproquós.

Os processos morais, imputados ou proferidos por Madan Olsen, devem ser apreendidos no contexto dessa malha de relações conflitivas e dos jogos de poder e de tensão que caracterizam as relações mediadas pela missão. 


\section{. Fiéis contra Madan Olsen}

Diversos fiéis da missão, diante da frequência reduzida de Madan Olsen e de Matante ao culto dominical depois que Madan Olsen foi despedida, diziam que "elas haviam caído (li chite)" (em referência aos anjos caídos) e não eram, portanto, "verdadeiras kretyèn". A acusação é reforçada quando ambas deixam definitivamente de frequentar todas as atividades da missão. Mesmo os mais próximos, que pensavam que a demissão tinha sido um fato "lamentável", aderiam a esse julgamento que tinha ares de simples constatação: não frequentavam mais a igreja, tinham "caído". Nos próximos meses e durante todo o ano de 2006, Madan Olsen vai tentar impor e difundir a sua própria versão dos fatos, buscando ganhar aliados. Parte desse esforço se materializa em processos acusatórios que ela lança contra outros, como veremos abaixo.

As informações que guarnecem os processos, Madan Olsen consegue graças ao seu talento do que Paine chamou de "gestão da informação (information management)", ou seja, da "art in arranging a constant flow of information to himself" (Paine 1967:282). Fundamental para isso, era o comércio em sua casa e a extensão de sua rede de parentesco espiritual (ela ou Olsen eram padrinhos de 22 crianças e padrinhos de casamento de mais de 30 casais). Como ela mesma me explicou: "Eu não ando, são as pessoas que vem me contar [as coisas]. São as palavras que andam (M'pa mache, moun vin di'm, se pawol ki mache, wi)". Ela entretém a relação com seus informantes levando em conta o que cada um pode lhe oferecer e acaba sabendo de muita coisa sobre a vida da missão, mesmo tendo sido excluída de lá. Ao mesmo tempo, fornece a conta-gotas informações sobre si mesma e sua família.

\section{. Madan Alekson em visita a Madan Olsen}

O processo que Madan Alekson faz à Madan Olsen é particular. Madan Alekson sabe que é de fora, que está entrando num campo de relações tensas. Vendo que Madan Olsen se afasta progressivamente 
da igreja, a esposa do novo pastor vai até a casa dessa 'ovelha' que começa a 'se desgarrar' lhe fazer uma visita. Este gesto (a visita, ir até o outro, em sua casa) é, e ambas sabem disso, uma forma de mostrar consideração, estima e respeito à pessoa visitada. Esse movimento virá então amortecer o impacto de suas palavras, que tomam a forma de um sermão que será dito em face a face. Madan Alekson convoca sua correligionária a não mais "se afastar de Deus" e de seus "irmãos em Cristo"; diz que, agindo assim, ela "caminha para o pecado". Madan Olsen recebe sua visitante cordialmente, mas rebate com firmeza suas recriminações: "Se há pecado, é nesta igreja que ele está". Diz que a igreja tem sido frequentada por "hipócritas e malfeitores" e que ler a Bíblia em casa, com "os seus", lhe parece o melhor a fazer. Recorre a Mateus para apoiar seu argumento: "Porque, onde estiverem dois ou três reunidos em meu nome, aí estou eu no meio deles" (Mateus 18:20). As duas mulheres não voltarão a conversar face a face.

\section{. Sorel contra os Olsen e os Olsen contra Sorel, sob a mediação dos missionários}

Madan Olsen nunca acreditou na conversão de Sorel, já que ele, em outros momentos da sua vida, se aproximou do protestantismo e sempre acabou voltando a suas antigas práticas Vodu. Nos dias seguintes à demissão de Madan Olsen, Sorel bateu-boca diretamente com Madan Olsen e também com sua mãe e com um irmão, por questões ligadas ao comércio.

O ex-ougan disse que Madan Olsen havia recusado-se a vender-lhe um pouco de óleo de cozinha, recusa que teria sido acompanhada de gestos escandalosos; já ela afirmou que simplesmente estava sem a mercadoria no estoque, por isso não pode efetuar a venda.

Em outra ocasião, na varanda de Matante, Sorel discutiu com a dona da casa e seu filho, dizendo que eles não queriam lhe dar o troco correto da compra de uma porção de cal. A desavença terminou com ameaças de morte recíprocas. A briga chegou ao ouvido dos missionários, que exigiram que Matante e seus filhos se desculpassem, pois eles 
eram "os mais velhos no evangelho", quando Sorel era um "recémnascido para Jesus".

Os três não só se recusaram, mas mostraram-se indignados com o pedido: “jamais me ajoelharei diante de um ougan”, disse Matante. Já Madan Olsen ironizou "vou lá sim, vou lá pedir desculpas com uma garrafa de rum na mão, uma vela e 50 dólares haitianos".

A partir de então, eles não perderão uma oportunidade de desqualificar a fé kretyèn de Sorel, "esse aí nunca deixou os negócios (zafe yo, referindo-se ao culto dos lwa)", "olha o nariz dela (referindo-se a esposa de Sorel), ela cheira rapé como o marido!” As acusações aproximam Sorel (e os seus) do seu passado no Vodu, negando a legitimidade da sua posição recente, de fiel evangélico, protegido dos missionários.

\section{- Madan Olsen contra a mãe de pastor Alekson}

Madan Olsen ouve dizer que a mãe de pastor Alekson teria dito que, se ela encontrasse no seu caminho quem se opusesse ao seu filho, ela iria "já vestir uma calça (m’ap mete kanson nan tay mwen)". A expressão remete ao universo masculino (a calça) para exprimir a ideia de uma força viril, de coragem, de capacidade de reação ou vingança, algo como "vocês vão ver do que sou capaz"28. Isto basta para que Madan Olsen comece a dizer, a suas comadres e a seus clientes, que isso é a prova de que a mulher "não hesitaria em recorrer a um ougan" para proteger seu filho, que ela "não é, nem de longe, tão pura quanto ela gostaria de parecer".

\section{- Matante e Madan Olsen contra Jonas}

Jonas, sobrinho de Yonyon, converteu-se pouco depois da chegada da missão em Mòn Anvè, mas Madan Olsen suspeita que ele "não abandonou o vício". Alguém disse a ela que outro alguém o teria visto sair da casa de um ougan (kay gangan). Ela fez circular a informação amplamente. 


\section{. Matante e Madan Olsen contra pastè John}

Nas lakou de Matante et de Madan Olsen, as duas afirmam que pastor John é um pastè tripotay, ou seja, um pastor-fofoca. Fazem assim alusão ao fato do pastor ter, na sua opinião, levado demais em consideração as fofocas que circulavam na missão contra elas. Não tentam aproximá-lo do Vodu, o que seria pouco plausível e possivelmente muito forte. Mas o associam a um outro comportamento reprovado na Bíblia.

\section{- Madan Olsen, em sonho, contra Madan John}

Para poder maldizer Madan John, Madan Olsen faz um desvio e passa por um sonho. Numa manhã, quando estávamos em seu comércio dois fiéis da igreja e eu, Madan Olsen chega, nos ouve um pouco e depois conta que sonhou com Madan John. As duas estavam, ela nos conta, na beira da estrada, não longe da missão. Madan John teria então confessado, sem tremer, que ela guardava só uma "partezinha bem pequenininha (yon ti kras)" do seu no seu coração para Jesus. Madan Olsen teria perguntado então à missionária se ela era realmente kretyèn, mas não teria obtido resposta, pois logo se acordou. Sentada na lakou, ela nos diz então, em tom de confissão, que sabe a resposta: Madan John "não é uma verdadeira kretyèn".

Madan John não era qualquer kretyèn, mas sim a missionária estabelecida ali há anos, que tanto tinha feito, na visão das mulheres presentes, pelas pessoas na região. Todos ali sabiam o peso dessa denúncia, justamente por ela ser dirigida à Madan John e não à outra pessoa. O sonho oferece então um meio, um caminho para que uma afirmação tão direta se materialize em palavras explícitas. É como se o sonho permitisse formular uma acusação que até ali, não havia podido ser feita abertamente. De fato, Madan Olsen só tinha, até então, feito críticas localizadas ao comportamento de Madan John, referindose ao modo como a missionaria agiu com ela e com sua mãe, nesse episódio específico da demissão. Dizia que a missionária não a tinha 
visitado quando ela esteve doente, que ela não a recebeu para discutir sobre a demissão. Mas ela nunca tinha dirigido uma crítica moral definitiva a missionária, a ela enquanto mulher kretyèn.

\section{Abnegação em nome da missão}

Para além das acusações de outros, em defesa do seu status de vrè kretyèn, Madan Olsen e Matante invocavam, de maneira teatral e emocionada, os sacrifícios que haviam feito em nome da missão. Com outros de sua família, haviam sido operários "de sol a sol", as mãos no cimento, para levantar cada parede; operários também "a serviço da palavra de Jesus", levando a "boa nova" pelas estradas e caminhos, até as casas mais afastadas. Madan Olsen teria abdicado de sua própria família e negócios para cuidar e ensinar o crioulo aos filhos de Madan John; Matante lembrava das horas a fio passando as roupas do casal, com um ferro a carvão, sem que ninguém viesse oferecer uma cadeira. Tudo isso por eles, pela missão, em nome da palavra de Jesus. $\mathrm{O}$ relato performático busca provocar uma nova leitura do passado, do presente e do projeto de futuro da missão. Põe em cena o papel capital da família na implantação da missão, centralidade que legitimaria a sua presença hegemônica na igreja e convidaria a questionar a mudança de direção em curso.

\section{Conclusão}

Joel Robbins (2004b), estudando os recém-convertidos Urapmin da Papua Nova Guiné, Christophe Pons (2011), os protestantes históricos das ilhas de Faroé, ou ainda Jarrett Zigon (2009), trabalhando com mulheres ortodoxas de Moscou, mostraram que uma parte importante das preocupações morais de seus interlocutores tomam a forma de dilemas morais individuais. Materializam-se em momentos em que indivíduo está diante de seus próprios atos ou confronta-se à questão de como viver como uma 'boa' pessoa. São, portanto, trabalhos que tratam majoritariamente da relação entre a moral e o 'self'. 
O julgamento moral de outros é também observado nestes contextos, mas a experiência moral dos indivíduos é lida, sobretudo, através do "trabalho moral sobre si mesmos" e através das inquietudes e tensões que nascem de situações que impõe um posicionamento, que obrigam a sair de uma "non-consciously enacted morality" (Zigon 2009:274). O título do trabalho de Joel Robbins (2004b) que se tornou seminal para a recente Antropologia do Cristianismo, Becoming sinners: Christianity and Moral Torment in a Papua New Guinea Society, é, por si só, evocador do peso do sentimento de culpabilidade que emerge da conversão dos Urapmin ao protestantismo evangélico.

Nas montanhas da Grand'Anse, as questões morais que ocupavam meus interlocutores não se apresentaram como angústias ou inquietudes sobre si mesmo (um indivíduo que se perguntaria se ele estaria agindo bem, se não estaria tornando-se um pecador), mas na forma de julgamentos morais sobre outros. É na apreciação do comportamento alheio que as premissas morais explicitam-se neste contexto. A avaliação moral de outros e de si mesmo não necessariamente se excluem, mas o protestantismo de inspiração batista da EBM não insistia sobre o imperativo de autoexame e sua implantação não parece ter provocado a emergência de um sentimento de culpabilidade entre os fiéis. $\mathrm{O}$ medo ou aflição de 'ver-se como um pecador' era praticamente ausente das falas dos meus interlocutores.

Antropólogos que trabalham sobre o Caribe já mostraram o quanto a inveja, as fofocas e a feitiçaria organizam as relações sociais nessa região, em contextos de interconhecimento (Abrahams 1983; Bougerol 1997; Affergan 2006). Esses três elementos, eles mesmos produtos e produtores de relações de poder, agenciam o cotidiano: vizinhos se observam, se espiam (há estratégias de observação assim como táticas para fugir de olhares indiscretos), perscrutam os movimentos uns dos outros, controlam ao mesmo tempo seus próprios gestos (porque sabem-se sob olhar dos outros) e falam do que viram ou pensam ter visto. As rivalidades, conflitos e desacordos são quase sempre precedidos ou acompanhados de fofocas e terminam com fre- 
quência em escândalos ou acusações de feitiçaria. As relações entre correligionários evangélicos no Haiti não rompem com esse modus operandi comunitário. Elas embrenham-se nele.

Se para alguns, o fato de tornar-se um pecador é o que provoca tormento moral, entre meus interlocutores, é possível dizer que a obsessão moral é a de definir quem é e quem não é um verdadeiro kretyen, e, afinal, fazer do outro um pecador.

\section{Notas:}

1 Mòn em crioulo haitiano (mornes em francês). As duas localidades vizinhas onde trabalho se situam entre 500 e 700 metros de altura. Essa pesquisa se apoia em dados empíricos obtidos durante o campo de pesquisa realizado para minha tese de doutorado entre 2005 e 2007.

2 O termo 'protestante' é usado aqui de forma genérica e abrangente (inclui pentecostais, evangélicos, adventistas e outras correntes históricas). Especificarei as correntes e denominações quando necessário. Já posso dizer que a maioria dos meus interlocutores que aparecem neste artigo são evangélicos (batistas).

3 Ver por exemplo Boltanski et al. 2007.

4 União conjugal costumeira, ou seja, não sancionada por uma instituição, mas reconhecida por todos.

5 A legalização do Vodu ocorreu sob o governo de Jean Bertrand Aristide em 2003 e foi precedida e acompanhada, como descreve Béchacq (2014), de um processo de institucionalização desta religião (criação de associações de defesa e promoção do culto, de uma federação nacional, etc.).

6 'Irmão' e 'irmã' são os termos com os quais fiéis, no protestantismo evangélico e pentecostal, se interpelam.

7 Para um estudo de caso sobre o pragmatismo e fluidez das escolhas religiosas no Haiti contemporâneo, ver Richman 2012. Sobre o Vodu e o catolicismo e suas permeabilidades no campesinato haitiano, ver Baptista 2012 e Richman op. cit.

8 Segundo Matthew Casey (2017), cerca de 200000 haitianos trabalharam nas plantações de açúcar no leste de Cuba nas primeiras décadas do século XX. A maior parte deles foram repatriados a força nos anos 1930.

9 Pastè em crioulo haitiano significa pastor e Madan significa senhora. As esposas ou companheiras reconhecidas como tal, no Haiti, ganham o primeiro nome do marido (ou companheiro), precedido de Madan.

10 Esse cenário não deve, no entanto, ser visto como definitivo. As 'desconversões' são frequentes e para um dos referidos ougan, essa era a sua sétima conversão. 
11 A descrição das atividades e do espaço da missão é feita aqui toda no passado, já que no final do ano de 2007, os missionários deixaram Haiti para que John tratasse de um câncer. Pouco tempo depois, a missão foi comprada por um outro casal de missionários protestantes norte-americanos, da missão The Torch Worship Center. 12 Durante muitos anos, Pastè John pensou em construir uma pista de aterrissagem, como seu tio, também missionário e diretor de EBM, tinha feito num vilarejo na Nova Guiné.

13 As pessoas chamam esse espaço delimitado da missão de lakou misyon, em referência ao lakou (do francês 'la cour'), termo que designa a ou as casas de um grupo residencial e o terreno (quintal) que as circunda.

14 Paula Montero, por exemplo, mostra como nas colônias missionárias salesianas do Brasil no século XX, "a força simbólica dos padres dependia em grande parte de sua prodigalidade em distribuir bens” (Montero 2012:193).

15 Os missionários instaurarão um comitê com cinco membros (além dos próprios missionários), com o objetivo de discutir o dia a dia da missão e as dificuldades e problemas que os fiéis podiam enfrentar.

16 A respeito do prazer em fazer fofocas, ver Besnier (2009:18-19 e 95-99).

17 Esta constatação (prática condenada e, no entanto, praticada por todos) é comum (Bougerol 1997:31-51; Besnier 2009:94-95; Abrahams 1983:79).

18 Ver por exemplo na Psicologia Fernandes, Kapoor \& Karandikar (2017) e na Filosofia Alfano \& Robinson (2017).

19 Sobre esse ponto, ver Pons (2011:17).

20 Se Lutero emitiu críticas às considerações de Tiago, Philip Jenkins nota que o texto se tornou central na pregação evangélica em países do sul, por "dirigir-se a fiéis pobres que devem fazer face a um stress constante e à tentação, sem cair no desespero e sem invejar os ricos" (2006:61).

21 Descrevendo supostas 'cerimônias Vodu', pastor John narrava cenas macabras onde bebês eram jogados de falésias, corpos de crianças desmembrados, havia sangue por toda parte...

22 Uma das expressões idiomáticas para dizer hipócrita é 'rat anba po (rato embaixo da pele)'.

23 Um equivalente da expressão brasileira 'rezar para todos os santos'.

24 O cristão autêntico 'dá a Deus a autoridade sobre sua vida (bay Bondye otorite sou lavi'l)', segundo as palavras de um pastor.

25 Ver, por exemplo: https://hellochristian.com/8130-12-signs-you-are-a-modernday-pharisee

26 O primeiro estudo de Calvino é dedicado a Sêneca (Ryrie 2013:18).

27 Clara C. J. Mafra, a partir do caso do pentecostalismo no Brasil, e revisitando a discussão de Keane sobre a sinceridade, afirma que "a formação da pessoa" pentecostal cristã se elabora não somente a partir da "ideologia da sinceridade", mas também da "ideologia da santidade". O pentecostalismo no Brasil se construiria num processo contínuo de distinção do catolicismo, como religião nacional e popular, e das religiões afro-brasileiras. Neste contexto, Mafra sugere que para os pentecostais 
brasileiros, a santidade se torna um objeto de disputa: "os pentecostais brasileiros parecem afirmar um subtexto que implica que a hierarquia atual de santidade, com a Igreja Católica como seu ponto de referência, deve ser invertida" (2014:181). Eles se oporiam, assim, ao "o modelo de pessoa sincrética", aquele dos católicos que fazem uma "utilização estratégica de diversas sintaxes, dependendo do evento ou situação" (2014: 182). A tese de Mafra não deixa de fazer sentido para pensar o caso dos pentecostais haitianos, já que ali também eles se afirmam opondo-se a "pessoas sincréticas".

28 Pode ser aproximada da expressão 'por o pau na mesa', em português.

\section{Referências:}

ABRAHAMS, Roger. 1983. The Man-of-Words in the West Indies. Performance and the Emergence of Creole Culture. Baltimore/London: The John Hopkins University.

AFFERGAN, Francis. 2006. Martinique, les Identités Remarquables. Anthropologie d'un terrain revisité. Paris: PUF.

AGGELER, Geoffrey. 1990. "'Sparkes Of Holy Things': Neostoicism And The English Protestant Conscience”. Renaissance and Reformation/ Renaissance et Réforme (New Series / Nouvelle Série), 14(3):223-240.

ALBERTS, Thomas. 2008. "Virtually real: Fake religions and problems of authenticity in religion." Culture and Religion, 9(2):125-139.

ALFANO, Mark, \& ROBINSON, Brian. 2017. "Gossip as a Burdened Virtue". Ethical Theory and Moral Practice, 20(3):473-487.

ALTHABE, Gérard. 1993. "Procès réciproques en HLM". In ALTHABE, Gérard et al. (eds.): Urbanisation et Enjeux Quotidiens. Terrains ethnologiques dans la France actuelle, pp.13-47. Paris: L'Harmattan.

BATISTA, José Renato. 2012. Uma etnografia sobre o universo social do Vodu Haitiano. Tese de doutorado em Antropologia. Rio de Janeiro : UFRJ/Museu Nacional.

BÉCHACQ, Dimitri. 2014. "Le secteur vodou en Haïti. Esthétique politique d'un militantisme religieux (1986-2010). ” Histoire, Monde et Cultures religieuses, 1(29):101-118.

BENSA, Alban. 2006. La Fin de l'Exotisme. Essais d'anthropologie critique. Toulouse: Anacharsis.

BERGMANN, Jörg. 1993. Discreet Indiscretions. The Social Organization of Gossip. New York: Aldine de Gruyter.

BERNHEIM, Pierre A. 2001. "Épître de Jacques et morale judéo-chrétienne." Pardès, 1(30):27-40.

BESNIER, Niko. 2009. Gossip and the Everyday Production of Politics. Honolulu: University of Hawaii Press. 
BOLTANSKI, Luc et al (eds). 2007. Affaires, Scandales et Grandes Causes : de Socrate à Pinochet. Paris: Stock.

BOUGEROL, Christiane. 2007. Une Ethnographie des Conflits aux Antilles: Jalousie, commérages, sorcellerie. Paris: PUF.

BRISON, Karen. 1992. Just Talk: Gossip, Meetings, and Power in a Papua New Guinea Village. Berkeley: University of California Press.

BRODWIN, Paul. 1996. Medicine and Morality in Haiti: The contest of healing power. Cambridge: Cambridge University Press.

CASEY, Matthew. 2017. Empire's Guestworkers: Haitian Migrants in Cuba during the Age of US Occupation. Cambridge: University of Cambridge Press.

CLORMÉUS, Lewis Ampidu. 2012. Entre l'État, les intellectuels et les religions. Redécouvrir la campagne anti-superstitieuse de 1939-1942. Tese de doutorado em Sociologia. Port-au-Prince: Université d'État d'Haïti.

COPEMAN, Jacob. 2012. "The mimetic guru: tracing the real in Sikh-Dera Sacha Sauda relations." In COPEMAN, J. \& IKEGAME, A. (eds.): The Guru in South Asia: new interdisciplinary perspectives, pp.156-180. London: Routledge.

CORTEN, André. 1998. "Un mouvement religieux rebelle en Haïti: l'Armée Céleste.” Conjonction, 203:53-62.

CORTEN, André, \& MARSHALL-FRATANI, Ruth. 2001. Between Babel and Pentecost. Transnational Pentecostalism in Africa and Latin America. Bloomington: Indiana University Press.

DALMASO, Flavia. 2018. "Heranças de família: terras, pessoas e espíritos no sul do Haiti." Mana, 24(3):96-123.

ELIAS, Norbert, \& SCOTSON, John. 1994 [1965]. The Established and the Outsiders: A Sociological Enquiry into Community Problems. London: Sage Publications.

ENGELKE, Matthew. 2004. "Discontinuity and the Discourse of Conversion." Journal of Religion in Africa, 34(1-2):82-109.

ERRINGTON, Frederick, \& GEWERTZ, Deborah. 1995. Articulating Change in the 'Last Unknown'. Boulder: Westview.

FATH, Sébastien (ed.). 2004. Le Protestantisme Evangélique, un Christianisme de Conversion. Turnhout: Brepols Publishers.

FERNANDES, S., KAPOOR, H. \& KARANDIKAR, S. 2017. "Do We Gossip for Moral Reasons? The Intersection of Moral Foundations and Gossip ?". Basic and Applied Social Psychology, 39(4):218-230.

GLUCKMAN, Max. 1963. "Gossip and scandal." Current Anthropology, 4:304-315.

GRAVES, Amy. 2006. "Les épreuves du huguenot et la vulgarisation du stoïcisme: Simon Goulart, Jean de L’Espine et Sénèque." Cahiers V.-L. Saulnier, 23:116-124.

GRIERA, Maria. 2008. "'Are you a real Christian?' Stereotypes, distrust and distinction strategies between 'new' and 'old' Protestants in Catalonia." Etnográfica, 12(2):403-423.

HURBON, Laënnec. 1988. Le Barbare Imaginaire. Paris: Éditions du Cerf. 
IRONS, William. 2001. "Religion as a hard-to-fake sign of commitment." In NESSE, Randolph (ed.): Evolution and the Capacity for Commtiment, pp.292309. New York: The Russel Sage Foundation.

JENKINS, Philip. 2006. The New Faces of Christianity: Believing the Bible in the Global South. New York: Oxford University Press.

KEANE, Webb. 1997. "From Fetishism to Sincerity: On Agency, the Speaking Subject, and their Historicity in the Context $f$ Religious Conversion." Comparative Studies in Society and History, 39(4):674-693. . 2002. "Sincerity, 'Modernity,' and the Protestants." Cultural Anthropology, $17(1): 65-92$.

LAGRÉE, Jacqueline. 2010. Le Néostoïcisme. Paris: Vrin.

LESTRINGANT, Frank. 2006. "Deux chrétiens face au stoïcisme : Montaigne et d'Aubigné." Cahiers V.-L. Saulnier, 23:9-16.

MAFRA, Clara. 2014. "Santidade e sinceridade na formação da pessoa cristã." Religião e Sociedade, 34(1):173-192.

MÉZIÉ, Nadège. 2016. "Emergência e ascensão dos protestantismos no Haiti: um panorama histórico." Debates do NER, 29(1):289-327.

MBEMBE, Achille. 1993. "La prolifération du divin en Afrique subsaharienne." In KEPEL, Gilles (ed.) : Les politiques de Dieu, pp.177-201. Paris: Éditions du Seuil.

MONTERO, Paula. 2012. Selvagens, Civilizados, Autênticos. A produção das diferenças nas etnografias salesianas (1920-1970). São Paulo: EDUSP/FAPESP.

NEAL, Lynn S. 2016. "OMG: Authenticity, Parody, and Evangelical Christian Fashion." Fashion Theory, 21(3):223-244.

ORO, A. P., CORTEN, A. \& DOZON, J.P. (eds.). (2003). Igreja Universal do Reino de Deus: os novos conquistadores da fé. São Paulo: Editora Paulinas.

PAINE. Robert. 1967. "What is gossip about? An alternative Hypothesis." Man, 2(2):278-285.

PIETILA, Tuulikki. 2007. Gossip, Markets, and Gender: How Dialogue Constructs Moral Value in Post-Socialist Kilimanjaro. Madison: The University of Wisconsin Press.

PONS, Christophe. 2011. "The Anthropology of Christianity in the Faroe Islands. What the fringes of the Faroe Religious Configuration have to say about Christianity". In GAINI, Firouz (ed.): Among the Islanders of the North. An Anthropology of the Faroe Islands, pp.80-131. Fróðskapur : Faroese University Press.

RAMSEY, Kate. 2011. Vodou and Power in Haiti: The Spirits and the Law. Chicago: The University Press of Chicago.

RICHMAN, Karen. 2008. "A more powerful sorcerer: conversion, capital, and haitian transnational migration." New West Indian Guide/Nieuwe West-Indische Gids, 82(1-2):3-45.

2012. "Religion at the Epicenter: Agency and Affiliation in Léogâne After the Earthquake." Studies in Religion/Sciences Religieuses, 41(2):148-165. 
ROBBINS, Joel. 2004a. "The Globalization of Pentecostal and Charismatic Christianity." Annual Review of Anthropology, 33:117-143. 2004b. Becoming Sinners: Christianity and Moral Torment in a Papua New Guinea Society. Berkeley: University of California Press.

RYRIE, Alec. 2013. Being Protestant in Reformation Britain. Oxford: Oxford University Press.

SHIPLEY, Jesse. 2009. "Comedians, pastors, and the miraculous agency of charisma in

Ghana." Cultural Anthropology, 24(3):523-552.

TODD, Margo. 1983. "Seneca and the Protestant Mind: The Influence of Stoicism on Puritan Ethics." Archiv für Reformationsgeschichte, 74:182-200.

ZIGON, Jarrett. 2009. "Within a Range of Possibilities : Morality and Ethics in Social Life." Ethnos 74(2):251-276.

\begin{abstract}
Who is a 'real' evangelical and who is a 'fake' one? In this text, I describe and analyze moral processes among evangelicals of the same church in a rural community in southwestern Haiti, where the truth of one's faith is put under suspicion. In the network of relations mediated by a US mission, the crossfire of accusations among believers reveals power disputes, competition for moral superiority, and a way of expressing moral concerns that does not take the form of self-reflexivity and guilt so common in protestant contexts. Sinners are the others, and to accuse someone else is an occasion to affirm one's own virtue.
\end{abstract}

Keywords: Moral, Evangelicals, Gossip, Haiti, Mission.

Recebido em Abril de 2019.

Aprovado em Julho de 2019. 